\title{
Effectiveness of isosorbide dinitrate in cyanide poisoning as a function of the administration timing
}

\author{
Ophir Lavon ${ }^{1,2^{*}}$, Amit Avrahami $^{3}$ and Arik Eisenkraft ${ }^{4}$
}

\begin{abstract}
Background: Better and safer antidotes against cyanide poisoning are needed. Prior study has shown a favorable effect of isosorbide dinitrate (ISDN) on the survival of cyanide-poisoned rabbits when administered as early as 1 min after poisoning. The aim of the current study was to further evaluate the efficacy of intravenous ISDN administered in clinically relevant timing for first responders.
\end{abstract}

Methods: A comparative animal study using 24 rabbits in 4 randomized study groups was performed. Animals were poisoned with intravenous potassium cyanide $(1 \mathrm{mg} / \mathrm{kg})$. Animals in Group 1 served as controls and received no treatment. Groups 2-4 animals were treated intravenously with ISDN (50 $\mu \mathrm{g} / \mathrm{kg})$ after poisoning; one group after $3 \mathrm{~min}$, another group after $5 \mathrm{~min}$ and the last after $7 \mathrm{~min}$. Animals were observed for $30 \mathrm{~min}$ after poisoning. The study endpoints included survival rate, clinical status, blood pressure, pulse per minute, blood lactate and $\mathrm{pH}$.

Results: Five of 6 animals (83.3\%) from every treatment group survived the whole observation period while all control untreated animals died. All the rabbits collapsed immediately after exposure, showing rapidly deteriorated vital signs with lactic metabolic acidosis (peak blood lactate levels of 18.1 to $19.0 \mathrm{mmol} / \mathrm{L}$ on average at 10 min post exposure). Vital signs, clinical scores, and blood gases of treated rabbits gradually improved.

Conclusion: Poisoned rabbits showed improved short-term survival following the administration of ISDN up to 7 min after lethal cyanide poisoning of. We see a potential for ISDN as an antidote against cyanide poisoning.

Keywords: Cyanide, Isosorbide dinitrate, Antidote, Poisoning, Animal

\section{Background}

The toxic chemical cyanide is frequently used in different industries $[1,2]$. Cyanide poisoning poses an imminent threat in various scenarios, both intentional and accidental $[1,3,4]$. Currently used antidotes have several major limitations. The expensive Hydroxocobalamin exerts its effects when given intravenously, and within 10 to $15 \mathrm{~min}$ [5]. Another intravenously

\footnotetext{
* Correspondence: ophir.lavon@clalit.org.il

${ }^{1}$ Clinical Pharmacology and Toxicology Unit, Carmel Medical Center, 7 Michal St., Haifa 3436212, Israel

${ }^{2}$ Rappaport Faculty of Medicine, Technion-Israel Institute of Technology, Haifa, Israel

Full list of author information is available at the end of the article
}

administered antidote is sodium thiosulfate, which also acts as a relatively slow antidote [6]. Nitrites have significant adverse reactions such as hypotension and profound dose-dependent methemoglobinemia. They also have relative contraindications in certain scenarios and populations [3, 6]. In a similar way, dicobalt edetate is given intravenously and has several safety issues $[1,6]$.

In a previous study we demonstrated that administration of intravenous isosorbide dinitrate (ISDN) within 1 min after lethal cyanide poisoning of rabbits improved their survival with full recovery of blood gases, vital signs and clinical scores [7]. 
ISDN, is a nitrate used pharmacologically as a vasodilator for angina (heart-related chest pain), congestive heart failure, and esophageal spasms [8].

The aim of the current work is to test whether the efficacy of intravenous ISDN depends on the timing from poisoning to therapy.

\section{Methods}

We have conducted a clinically relevant animal study using a methodology previously reported [7]. Twenty four rabbits were studied, divided into 4 study groups. Group 1 animals were not treated after poisoning and served as controls. The animals of groups 2-4 were treated intravenously with ISDN $(50 \mu \mathrm{g} / \mathrm{kg})$ after poisoning; group 2 after $3 \mathrm{~min}$, group 3 after $5 \mathrm{~min}$ and the group 4 after $7 \mathrm{~min}$. These doses are weight-equivalent to human doses. The study endpoints included survival rate, clinical status (presented by a score that was developed for our previously reported study), pulse per minute, BP (blood pressure), blood lactate, and $\mathrm{pH}$. The observation time was up to $1 / 2$ an hour. Prior to the start of each research day the poison solution and the medication were specially prepared in a method previously reported [7]. Appropriate vascular accesses were prepared in the rabbit ear. Arterial blood probe was attached to monitor the vital signs. This monitoring system was successfully used in our previously reported study [7].

The calculated cyanide poison dose was intravenously injected. The ISDN was intravenously administered 3, 5 or $7 \mathrm{~min}$ after poisoning (depending on the study group). During the continuous observation, outcomes were recorded in time points set in advance; vital signs every minute, clinical score at $0,1,2,3,4,5,7$, 10, 15, $30 \mathrm{~min}$, and blood sample at $0,2,5,10,15$, $30 \mathrm{~min}$. The clinical score included $6^{\circ}$ from death $(0)$ to fully alert and moving (5). Blood sampling and laboratory analysis was completed in a previously reported method [7].
Comprehensive data analysis was conducted using SPSS Statistics version 22, IBM ${ }^{\bullet}$.

\section{Results}

Five of 6 rabbits $(83.3 \%)$ from every treatment group survived the whole 30 min observation period. All untreated animals died. The single animal per treatment group that did not survive died in the time range of 8 to 13 min after poisoning; the untreated control animals died in a median time to death of $8 \mathrm{~min}$ (range 2 to $15 \mathrm{~min}$ ). All rabbits collapsed within $1 \mathrm{~min}$ of exposure, with the clinical score falling sharply from 5 to 1 . All rabbits showed generalized tonic-clonic convulsions, most probably seizures, within 25 to $40 \mathrm{~s}$ of exposure; clinical status then deteriorated into complete unresponsiveness. The animals treated $3 \mathrm{~min}$ after poisoning had a trend for better clinical scores when compared to animals receiving the treatment later, from 4 min after exposure and until the end of observation. This was not statistically significant when evaluated with One-Way ANOVA test. Time vs. average clinical scores are shown in Fig. 1.

We found a considerable drop in pulse post exposure from average pulse rates of 240-272 per min preexposure to 66-104 per min after $1 \mathrm{~min}$. Mean BP increased from average values of $67-74 \mathrm{mmHg}$ before poisoning to $84-111 \mathrm{mmHg} 1 \mathrm{~min}$ after intoxication. Steady improvement of BP and pulse to baseline levels was found in all treated rabbits, while several variations were seen between groups. Pulse values at 4 to $8 \mathrm{~min}$ post intoxication were significantly higher in the $3 \mathrm{~min}$ group compared to the other groups $(p<0.05$, One-Way ANOVA). Average mean BP and pulse data are presented in Figs. 2 and 3.

Shortly after poisoning, blood $\mathrm{pH}$ increased, representing a self-limited phase of hyperventilation, and then fallen to profound acidosis. Steady improvement was observed in all treated rabbits, yet baseline $\mathrm{pH}$ levels were not reached until the end of the observation period.

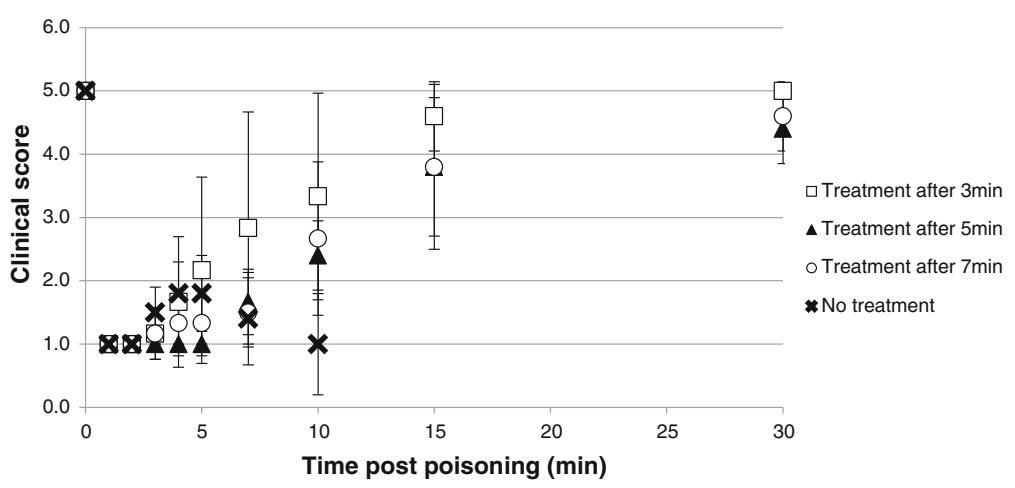

Fig. 1 Mean clinical scores $( \pm S D)$ 


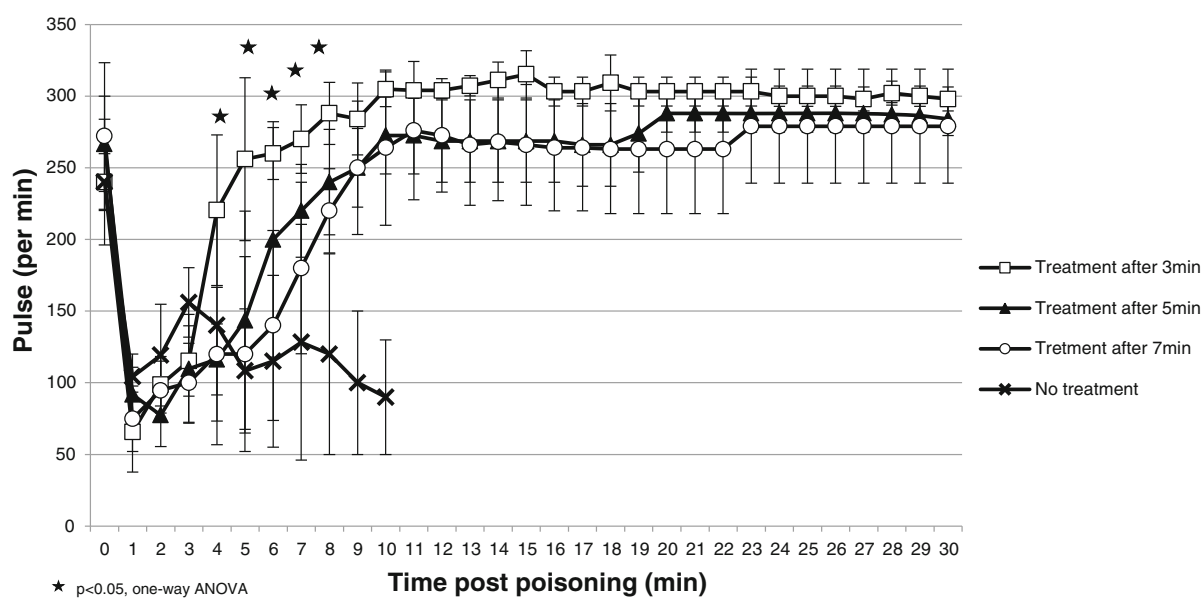

Fig. 2 Mean pulse (beats per $\min \pm S D$ )

Animals treated $3 \mathrm{~min}$ post exposure had significantly higher and closer to normal range $\mathrm{pH}$ values at the 15 and $30 \mathrm{~min}$ after poisoning time points $(p=0.012$ and $p=0.038$, respectively, One-Way ANOVA). Results of blood $\mathrm{pH}$ are shown in Fig. 4.

We found a gradual increase in lactate levels, peaked 10 min after poisoning in all groups. A slow return towards baseline levels was found in all treated rabbits but it did not return to baseline until the end of the observation period. Lactate levels were significantly lower and closer to normal range in the 3 min treatment group compared to the other later treated groups at $30 \mathrm{~min}$ post poisoning (averages 13.5 vs. 17.3 and $18 \mathrm{mmol} / \mathrm{L}, p=0.04$, One-Way ANOVA). Average lactate results are presented in Fig. 5.

\section{Discussion}

The study results demonstrate clear effectiveness of intravenous ISDN administered up to $7 \mathrm{~min}$ after lethal cyanide poisoning in increasing the short-term survival of poisoned rabbits. This observation strengthens previous study results that showed survival improvement with ISDN given $1 \mathrm{~min}$ after cyanide poisoning in rabbits [7]. The importance and contribution of the current study is the evidence it provides for ISDN clinical effectiveness in a realistic time frame for first responders (estimated to be several minutes) and its relevance as an antidote for cyanide. ISDN effectiveness was demonstrated in clinically relevant doses $(50 \mu \mathrm{g} / \mathrm{kg})$, supporting its role as a potential medical countermeasure in emergency clinical settings.

The vital signs (both pulse and BP) and clinical scores of the treated rabbits improved steadily after receiving the drug while untreated animals deteriorated until death. Earlier treatment (3 $\mathrm{min}$ after poisoning) improved relatively faster the clinical status of the animals back to baseline. Statistically significant difference

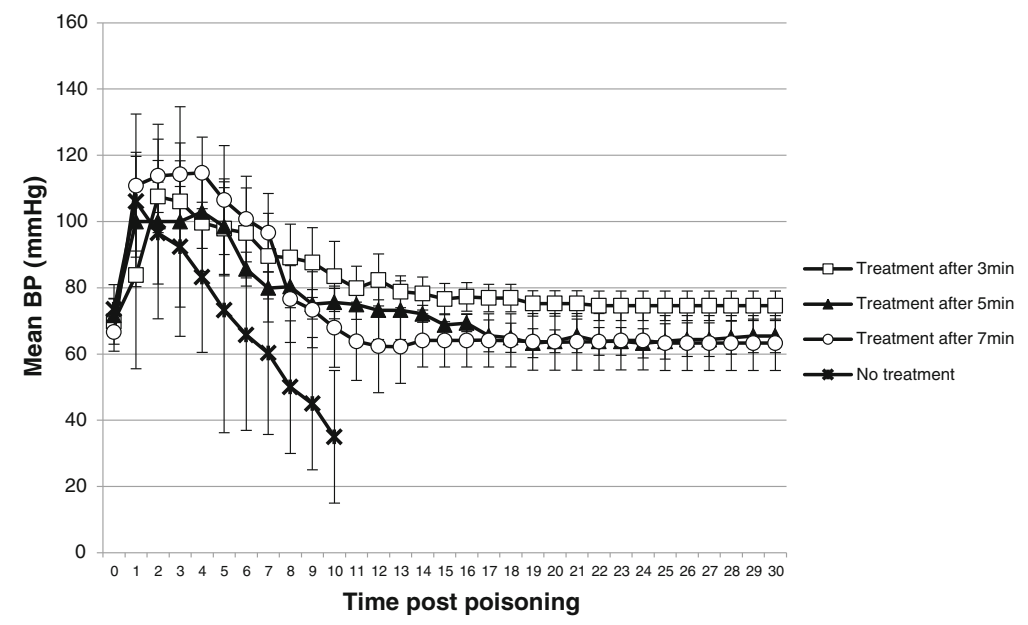

Fig. 3 Mean blood pressure $(\mathrm{mmHg} \pm \mathrm{SD})$ 


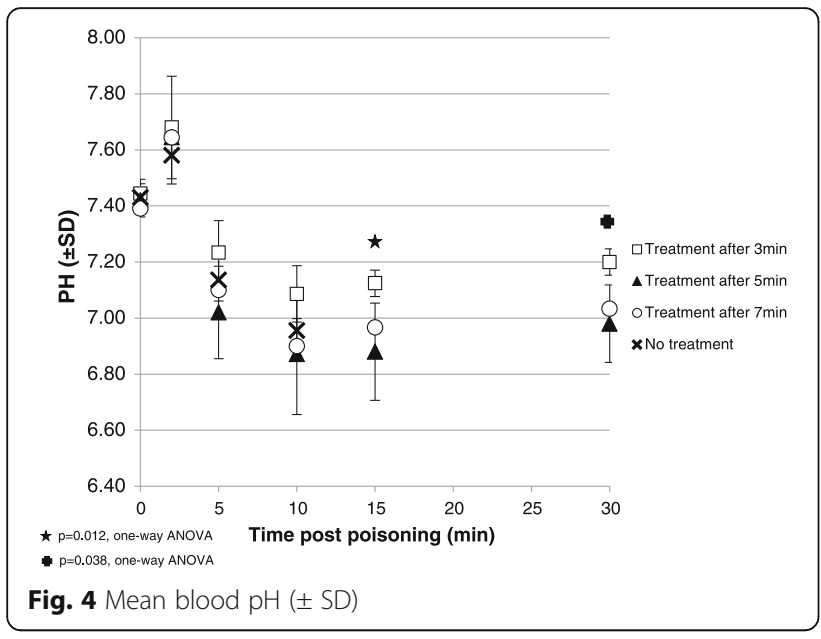

between the 3 min group and the other two treatment groups was calculated for the pulse values at 4 to $8 \mathrm{~min}$ after poisoning; this may be an evidence for the superiority of early treatment. Nevertheless, there were no statistically significant differences between the treatment groups in any of the other clinical endpoints including clinical scores, BP values and pulse rates beyond $8 \mathrm{~min}$ post poisoning. This represents meaningful and beneficial effects of ISDN administration up to 7 min post poisoning, not only on mere survival but also on clinical parameters.

The recovery of blood lactate and $\mathrm{pH}$ levels in the treated rabbits was less obvious than the improvement of the clinical endpoints but still evident. Baseline values were not achieved up to the end of the observation period. It seems that metabolic improvement is lagging after the clinical course. Perhaps a longer duration of observation will demonstrate full improvement of $\mathrm{pH}$ and lactate to normal range. Significant differences in $\mathrm{pH}$ (at 15 and $30 \mathrm{~min}$ post poisoning) and lactate (at 30 min post poisoning) levels were observed between the earlier treated animals to the other two treatment

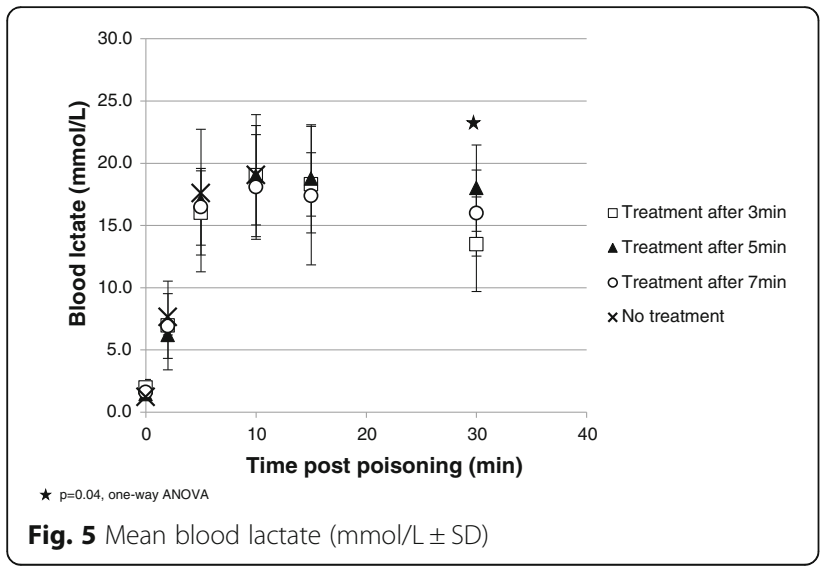

groups; early treatment is superior in improving lactic metabolic acidosis after cyanide poisoning. Yet, even later treatment of up to $7 \mathrm{~min}$ after poisoning resulted in the improvement of acidosis.

The presented animal model correlates well with a human poisoning. The main mechanism of cyanide poisoning in humans and other mammals include the inhibition of cytochrome oxidase $\mathrm{C}$ and the impairment of the aerobic metabolism in the mitochondria [1]. Cyanide toxicity occurs because this compound strongly binds to metals, inactivating metalloenzymes such as cytochrome c oxidase [2]. cyanide causes apoptotic cell death that is caspase-dependent and associated with mitochondrial membrane depolarization and cytochrome c release [9].

Lethal Cyanide poisoning exerts a distinctive clinical course $[7,10]$. This was clearly demonstrated in the current study. Exposure to cyanide leads to a drastic initial elevation of BP, probably due to vasoconstriction. This sharp increase in afterload can increase the oxygen demand and the heart's load, thus impairing cardiac output. This may lead to myocardial ischemia and bradycardia.

Another prominent clinical observation was the early development of seizures. Cyanide, through disruption of brain glutamatergic transmission, induces apnea and seizures [11]. In rats, within $30 \mathrm{~s}$ after exposure to cyanide, glutamate levels increase in several brain regions [12]. Inward currents produced by the NMDA receptor which can potentiate glutamatergic activity are also enhanced by cyanide [13].

Nitrates are rapidly reduced to nitric oxide $(\mathrm{NO})$ in blood and in tissues, in a NO synthase-independent pathway [14, 15]. The production of $\mathrm{NO}$ is increased gradually as oxygen tensions falls $[16,17]$. NO leads to vasodilatation, that can improve vascular bed ischemia, via the relaxation of muscle cells $[18,19]$. Vasodilatation reduces the afterload (arterial pressure) and the preload (the pressure of the blood returning to the heart) [20]. NO may also increase the oxygen supply to the heart, through reduction of coronary spasm. The administration of nitrates as ISDN in acute coronary events, ameliorates myocardial ischemia by improving coronary flow and decreasing cardiac workload [21, 22]. Phenoxybenzamine and chlorpromazine - other vasodilators-can also improve survival after exposure to cyanide [23-25]. NO-induced vasodilatation seems to have a beneficial role in cyanide intoxication.

The severity of the lactic acidosis as expressed by the blood lactate and $\mathrm{pH}$ levels was not different between treated and untreated animals in the study while a clear difference was observed regarding the vital signs' dynamics. It seems that the circulatory improvement of the treated animals was better predictive and correlated with their survival compared with their metabolic status. 
This supports the suggested mechanism of action of ISDN in cyanide exposure, improved circulation.

NO has direct antagonistic effect on cyanide in the mitochondrial electron transport chain, as it competes with it for binding to cytochrome c oxidase [26, 27]. Leavesley et al. demonstrated in an animal model that addition of exogenous $\mathrm{NO}$ attenuated cyanide inhibition of cytochrome c oxidase [27]. The same was observed when sodium nitrite was used as the source of NO that interacted directly with the binding of potassium cyanide with cytochrome c oxidase to reverse toxicity [28]. Also, it seems as if NO protects enzymatic systems from cyanide inactivation via a mechanism involving the formation of an enzyme-nitrosyl cyanide complex [29].

Brain NMDA-receptor hyperactivity reduction is another potential mechanism of NO protection in cyanide poisoning. $\mathrm{NO}+$ ion protects from excessive stimulation of the NMDA receptor by binding to its redox regulatory site [30]. This may attenuate repeated seizures as seen in the current study after ISDN administration.

The direct and independent antidotal activity of $\mathrm{NO}$ in cyanide poisoning is probably a more important and faster mechanism of nitrites and nitrates as cyanide antidotes than methemoglobin formation. Several animal and human studies showed that nitrites (sodium and amyl) improved survival in cyanide poisoning without forming significant levels of methemoglobin [7, 11, 31-33]. Production rate of methemoglobin by nitrites is relatively slow in humans [34]. The reported early recovery of severe cyanide poisoned victims following nitrite treatment is too fast to be explained by methemoglobin formation $[31,35,36]$.

While nitrates in therapeutic doses do not form methemoglobin, they were not considered relevant for cyanide poisoning. However, as it is shown and proven that $\mathrm{NO}$ antagonism is a principle mechanism in cyanide treatment, nitrates should be incorporated in the protocols implemented in cyanide exposure and poisoning particularly in the field setup or in mass casualty incidents.

Nitrates present several advantages over currently used antidotes. Nitrates are an approved, safe, and low cost treatment, easily available and widely used; particularly in cardiac patients [37-40]. There are various rapidly absorbed formulations with easy and effective application in pre-hospital setups, even by laymen [38]. Nitrates have no significant interactions with other cyanide antidotes or resuscitation medications [37, 38].

The study has several limitations. It is a limited number rabbit study with a short-term follow up period. Exposure to cyanide was achieved in the intravenous route, which is not the usual human exposure route. The investigators were not blinded to the control and treatment groups.

\section{Conclusion}

Intravenous administration of ISDN up to $7 \mathrm{~min}$ after minimally lethal cyanide poisoning improved the shortterm survival of poisoned rabbits. ISDN shows marked potential as an antidote for cyanide poisoning. Further research is needed to evaluate the effectiveness of nitrates in other modes of delivery, different animal models and poisoning scenarios.

\section{Acknowledgements \\ The authors acknowledge Dr. Gary Rockwood for his helpful comments. \\ Funding \\ The study was funded by the Israel Ministry of Defense.}

Availability of data and material

Crude data files of the study results are available upon request to the author of correspondence.

\section{Authors' contribution}

OL conceived the study; OL and AA designed the trial; OL and AE obtained research funding; $\mathrm{OL}, \mathrm{AA}$ and $\mathrm{AE}$ performed the study; $\mathrm{OL}$ completed the statistical analysis; OL drafted the manuscript, and all authors contributed substantially to its revision. OL takes responsibility for the paper as a whole. All authors read and approved the final manuscript.

\section{Competing interests}

The authors declare that they have no competing interests.

\section{Consent for publication}

Not applicable.

\section{Ethics approval}

The study was approved by the Rappaport Faculty of Medicine Institutional Animal Care and Use Committee.

\section{Author details}

${ }^{1}$ Clinical Pharmacology and Toxicology Unit, Carmel Medical Center, 7 Michal St., Haifa 3436212, Israel. ${ }^{2}$ Rappaport Faculty of Medicine, Technion-Israel Institute of Technology, Haifa, Israel. ${ }^{3}$ Pre Clinical Research Authority,

Technion-Israel Institute of Technology, Haifa, Israel. ${ }^{4}$ Institute for Research in Military Medicine, Faculty of Medicine, Hebrew University, Jerusalem, Israel.

Received: 9 September 2016 Accepted: 4 February 2017

Published online: 14 March 2017

References

1. Vogel SN, Sultan $\mathrm{CH}$, Jeneyck RP. Cyanide poisoning. J Toxicol Clin Toxicol. $1981 ; 18: 361-83$

2. Luque-Almagro VM, Moreno-Vivián C, Roldán MD. Biodegradation of cyanide wastes from mining and jewellery industries. Curr Opin Biotechnol. 2016:38:9-13.

3. Lavon O, Bentur Y. Does amyl nitrite have a role in the management of prehospital mass casualty cyanide poisoning? Clin Toxicol. 2010;48:477-84.

4. Tarantino G, Capone D, Finelli C. Exposure to ambient air particulate matter and non-alcoholic fatty liver disease. World J Gastroenterol. 2013;19:3951-6.

5. Thompson JP, Marrs TC. Hydroxocobalamin in cyanide poisoning. Clin Toxicol. 2012;50:875-85.

6. Marrs TC. Antidotal treatment of acute cyanide poisoning. Adverse Drug React Acute Poisoning Rev. 1988;4:179-206.

7. Lavon O. Early administration of isosorbide dinitrate improves survival of cyanide-poisoned rabbits. Clin Toxicol. 2015;53:22-7.

8. Zhao N, Xu J, Singh B, Yu X, Wu T, Huang Y. Nitrates for the prevention of cardiac morbidity and mortality in patients undergoing non-cardiac surgery. Cochrane Database Syst Rev. 2016;8:Art No. CD010726.

9. Tarantino G, Colao A, Capone D, Conca P, Tarantino M, Grimaldi E, et al. Circulating levels of cytochrome $\mathrm{C}$, gamma-glutamyl transferase, triglycerides and unconjugated bilirubin in overweight/obese patients with non-alcoholic fatty liver disease. J Biol Regul Homeost Agents. 2011;25:47-56. 
10. Vick JA, Froehlich HL. Studies of cyanide poisoning. Arch Int Pharmacodyn. 1985;273:314-22

11. Sun P, Borowitz JL, Kanthasamy AG, Kane MD, Gunasekar PG, Isom GE. Antagonism of cyanide toxicity by isosorbide dinitrite: possible role of nitric oxide. Toxicology. 1995;104:105-11.

12. Persson SA, Cassel G, Sellström A. Acute cyanide intoxication and central transmitter systems. Fundam Appl Toxicol. 1985;5:S150-9.

13. Patel MN, Peoples RW, Yim GK, Isom GE. Enhancement of NMDA-mediated responses by cyanide. Neurochem Res. 1994;19:1319-23.

14. Zweier JL, Wang P, Samouilov A, Kuppusamy P. Enzyme-independent formation of nitric oxide in biological tissues. Nat Med. 1995;1:804-9.

15. Cosby K, Partovi KS, Crawford JH, Patel RP, Reiter CD, Martyr S, et al. Nitrite reduction to nitric oxide by deoxyhemoglobin vasodilates the human circulation. Nat Med. 2003;9:1498-505.

16. Giraldez RR, Panda A, Xia Y, Sanders SP, Zweier JL. Decreased nitric-oxide synthase activity causes impaired endothelium-dependent relaxation in the postischemic heart. J Biol Chem. 1995:272:21420-6.

17. Oestergaard L, Stankevicius E, Andersen MR, Eskildsen-Helmond Y, Ledet T, Mulvany MJ, et al. Diminished NO release in chronic hypoxic human endothelial cells. Am J Physiol Heart Circ Physiol. 2007;293:H2894-903.

18. Ignarro LJ. Endothelium-derived nitric oxide: pharmacology and relationship to the actions of organic nitrate esters. Pharm Res. 1989;6:651-9.

19. Egashira K. Clinical importance of endothelial function in arteriosclerosis and ischemic heart disease. Circ J. 2002;66:529-33.

20. Wennmalm A. Endothelial nitric oxide and cardiovascular disease. J Intern Med. 1994;235:317-27.

21. Gray R, Chatterjee K, Vyden JK, Ganz W, Forrester JS, Swan HJ. Hemodynamic and metabolic effects of isosorbide dinitrate in chronic congestive heart failure. Am Heart J. 1975;90:346-52.

22. Chatterjee K. Hemodynamic effects of nitrates in chronic heart failure and myocardial infarction. Nouv Presse Med. 1980;9(34 Suppl):2404-9.

23. Dodson RA, Burrows GE, Isom GE, Way JL. Mechanism of chlorpromazine antagonism of cyanide intoxication. Proc West Pharmacol Soc. 1975;18:348-50.

24. Way JL, Burrows G. Cyanide intoxication: protection with chlorpromazine. Toxicol Appl Pharmacol. 1976;36:93-7.

25. Burrows GE, Way JL. Antagonism of cyanide toxicity by phenoxybenzamine. Fed Proc. 1975;35:250-1.

26. Shiva S, Huang Z, Grubina R, Sun J, Ringwood LA, MacArthur PH, et al. Deoxymyoglobin is a nitrite reductase that generates nitric oxide and regulates mitochondrial respiration. Circ Res. 2007:100:654-61.

27. Leavesley HB, Li L, Prabhakaran K, Borowitz JL, Isom GE. Interaction of cyanide and nitric oxide with cytochrome c oxidase: Implications for acute cyanide toxicity. Toxicol Sci. 2008;101:101-11.

28. Leavesley HB, Li L, Mukhopadhyay S, Borowitz JL, Isom GE. Nitrite-mediated antagonism of cyanide inhibition of cytochrome c oxidase in dopamine neurons. Toxicol Sci. 2010;115:569-76.

29. Pintus F, Spanò D, Bellelli A, Angelucci F, Forte E, Medda R, et al. Nitric oxide, substrate of Euphorbia characias peroxidase, switches off the $\mathrm{CN}(-)$ inhibitory effect. FEBS Open Bio. 2012;2:305-12.

30. Lipton SA, Choi YB, Pan ZH, Lei SZ, Chen HS, Sucher NJ, et al. A redox-based mechanism for the neuroprotective and neurodestructive effects of nitric oxide and related nitroso-compounds. Nature. 1993;364:626-32.

31. Johnson WS, Hall AH, Rumack BH. Cyanide poisoning successfully treated without 'therapeutic methemoglobin levels'. Am J Emerg Med. 1989;7:437-40.

32. Cambal LK, Swanson MR, Yuan Q, Weitz AC, Li HH, Pitt BR, et al. Acute, sublethal cyanide poisoning in mice is ameliorated by nitrite alone: complications arising from concomitant administration of nitrite and thiosulfate as an antidotal combination. Chem Res Toxicol. 2011;24:1104-12.

33. Dias-Junior CA, Gladwin MT, Tanus-Santos JE. Low-dose intravenous nitrite improves hemodynamics in a canine model of acute pulmonary thromboembolism. Free Radic Biol Med. 2006;41:1764-70.

34. Pluta RM, Oldfield EH, Bakhtian KD, Fathi AR, Smith RK, Devroom HL, et al. Safety and feasibility of long-term intravenous sodium nitrite infusion in healthy volunteers. PLoS One. 2011;6:e14504.

35. Lam KK, Lau FL. An incident of hydrogen cyanide poisoning. Am J Emerg Med. 2000;18:172-4.

36. Wurzburg H. Treatment of cyanide poisoning in industrial setting. Vet Hum Toxicol. 1996:38:44-7.

37. Seifert SA. Nitrates and nitrites. In: Dart RC, Cavarati EM, McGuigan MA Whyte IA, Dawson AH, Seifert SA, et al., editors. Medical Toxicology. 3rd ed. Philadelphia: Lippincot Williams \& Wilkins; 2004. p. 1177-8.
38. Murad F. Drugs used for treatment of angina: organic nitrates, calcium channel blockers and beta-adrenergic antagonists. In: Gilman AG, Rall TW Nies AS, Taylor P, editors. Goodman and Gilman's the pharmacological basis of therapeutics. 8th ed. New York: Pergam Press; 1990. p. 764-73.

39. Abrams J. Beneficial actions of nitrates in cardiovascular disease. Am J Cardiol. 1996;77:31C-7C

40. Nossaman VE, Nossaman BD, Kadowitz PJ. Nitrates and nitrites in the treatment of ischemic cardiac disease. Cardiol Rev. 2010;18:190-7.

\section{Submit your next manuscript to BioMed Central and we will help you at every step:}

- We accept pre-submission inquiries

- Our selector tool helps you to find the most relevant journal

- We provide round the clock customer support

- Convenient online submission

- Thorough peer review

- Inclusion in PubMed and all major indexing services

- Maximum visibility for your research

Submit your manuscript at www.biomedcentral.com/submit 